\title{
Perfil zoossanitário de propriedades leiteiras no sul do Rio Grande do Sul, Brasil
}

\author{
Animal health profile of dairy farms in southern Rio Grande do Sul, Brazil \\ Perfil de sanidad animal de las granjas lecheras en el sur de Rio Grande do Sul, Brasil
}

Recebido: 31/08/2021 | Revisado: 07/09/2021 | Aceito: 15/09/2021 | Publicado: 17/09/2021

\author{
Márcio Josué Costa Irala \\ ORCID: https://orcid.org/0000-0002-1284-1013 \\ Universidade Federal de Pelotas, Brasil \\ E-mail: marvetirala@gmail.com \\ Vitor Campos Assumpção de Amarante \\ ORCID: https://orcid.org/0000-0002-0576-0442 \\ Universidade Federal de Pelotas, Brasil \\ E-mail: vitor_amarante@hotmail.com \\ Bianca Conrad Bohm \\ ORCID: https://orcid.org/0000-0002-2947-706X \\ Universidade Federal de Pelotas, Brasil \\ E-mail: biankabohm@ @otmail.com \\ Laura Aparecida Martins de Moraes \\ ORCID: https://orcid.org/0000-0003-3672-8020 \\ Universidade Federal de Pelotas, Brasil \\ E-mail: laura_m_moraes@outlook.com \\ Fernanda de Rezende Pinto \\ ORCID: https://orcid.org/0000-0002-0794-1984 \\ Universidade Federal de Pelotas, Brasil \\ E-mail: f_rezendevet@yahoo.com.br \\ Fernando da Silva Bandeira \\ ORCID: https://orcid.org/0000-0001-9795-8124 \\ Universidade Federal de Pelotas, Brasil \\ E-mail: bandeiravett@gmail.com \\ Fábio Raphael Pascoti Bruhn \\ ORCID: https://orcid.org/0000-0002-4191-965X \\ Universidade Federal de Pelotas, Brasil \\ E-mail: fabio_rpb@yahoo.com.br
}

\begin{abstract}
Resumo
O Estado Rio Grande do Sul tem papel de destaque na produção de leite em âmbito nacional e a região sul do estado se destaca como uma das principais bacias leiterias do Estado. Objetivou-se com este estudo caracterizar o perfil zootécnico e sanitário em 51 rebanhos bovinos na microrregião de Pelotas. A partir das informações obtidas por meio de entrevistas construiu-se um banco de dados e obteve-se a descrição dos dados pela indicação de como variam os indivíduos no grupo. Neste estudo, as propriedades apresentaram a mediana de quatro moradores $(\mathrm{DI}=3)$ e tempo na pecuária leiteira de 20 anos $(\mathrm{DI}=26)$, a área total foi de 40 ha $(\mathrm{DI}=57)$, sendo a área destinada exclusivamente a produção leiteira (instalações para os animais e áreas de descanso e pastoreio) de 23 ha $(\mathrm{DI}=32)$. As propriedades apresentaram uma mediana de 20 vacas em lactação $(\mathrm{DI}=26)$ e cinco vacas secas $(\mathrm{DI}=7)$, o efetivo de novilhas a partir de um ano de idade foi nove (DI=16) e o efetivo de terneiras com menos de um ano foi oito (DI=11), o efetivo total do rebanho foi de 44 animais $(\mathrm{DI}=63)$. Foi avaliado o efetivo de outras espécies de animais domésticos como cães, equinos, galinhas, suínos, ovinos e caprinos. Foram observadas medianas de três cães $(\mathrm{DI}=3)$, dois equinos $(\mathrm{DI}=1,75)$, 30 galinhas $(\mathrm{DI}=30)$, três suínos $(\mathrm{DI}=4)$, quatro ovinos $(\mathrm{DI}=10)$ e cinco caprinos $(\mathrm{DI}=3)$. Os resultados deste estudo indicam que há uma grande heterogeneidade e uma baixa pluriatividade agrícola no processo produtivo de leite no sul do Rio Grande do Sul, sustentado principalmente por pequenas propriedades, baseado na mão de obra familiar e associado ao uso de tecnologias como a inseminação artificial e ordenha mecânica.
\end{abstract}

Palavras-chave: Bovinos; Perfil sanitário; Epidemiologia.

\begin{abstract}
The State of Rio Grande do Sul has a prominent role in milk production nationwide and the southern region of the state stands out as one of the main dairy basins in the State. The objective of this study was to characterize the zootechnical and sanitary profile in 51 bovine herds in the microregion of Pelotas. From the information obtained through interviews, a database was built and a description of the data was obtained by indicating how the individuals in the group vary. In this study, the properties had a median of four residents $(\mathrm{DI}=3)$ and time spent in dairy farming of 20 years $(\mathrm{DI}=26)$, the total area was $40 \mathrm{ha}(\mathrm{DI}=57)$, and the area was exclusively dedicated to production. dairy (animal facilities and rest and grazing areas) of $23 \mathrm{ha}(\mathrm{DI}=32)$. The properties presented a median of 20 lactating cows
\end{abstract}


(DI=26) and five dry cows (DI=7), the number of heifers from one year of age was nine (DI=16) and the number of heifers with less of one year was eight $(\mathrm{DI}=11)$, the total herd herd was 44 animals $(\mathrm{DI}=63)$. The effective of other species of domestic animals such as dogs, horses, chickens, swine, sheep and goats was evaluated. Medians of three dogs $(D I=3)$, two horses (DI=1.75), 30 chickens $(D I=30)$, three swine (DI=4), four sheep (DI=10) and five goats $(\mathrm{DI}=\mathrm{DI})$ were observed. $=3$ ). The results of this study indicate that there is great heterogeneity and low agricultural pluriactivity in the milk production process in southern Rio Grande do Sul, supported mainly by small properties, based on family labor and associated with the use of technologies such as artificial insemination and mechanical milking.

Keywords: Cattle; Sanitary profiles; Epidemiology.

\section{Resumen}

El estado de Rio Grande do Sul tiene un papel destacado en la producción de leche a nivel nacional y la región sur del estado se destaca como una de las principales cuencas lecheras del estado. El objetivo de este estudio fue caracterizar el perfil zootécnico y sanitario en 51 hatos bovinos de la microrregión de Pelotas. A partir de la información obtenida a través de entrevistas, se construyó una base de datos y se obtuvo una descripción de los datos indicando cómo varían los individuos del grupo. En este estudio, las propiedades tenían una mediana de cuatro habitantes $(\mathrm{DI}=3)$ y un tiempo de permanencia en la ganadería de 20 años $(\mathrm{DI}=26)$, el área total fue de 40 ha $(\mathrm{DI}=57)$, con el área dedicada exclusivamente a producción lechera (instalaciones para animales y áreas de descanso y pastoreo) de $23 \mathrm{ha}(\mathrm{DI}=32)$. Las propiedades presentaron una mediana de 20 vacas lactantes $(\mathrm{DI}=26)$ y cinco vacas secas $(\mathrm{DI}=7)$, el número de novillas a partir de un año de edad fue de nueve $(\mathrm{DI}=16)$ y el número de novillas con menos de un año. fue de ocho (DI = 11), el rebaño total fue de 44 animales $(\mathrm{DI}=63)$. Se evaluó la efectividad de otras especies de animales domésticos como perros, caballos, pollos, cerdos, ovejas y cabras. Las medianas de tres perros (DI = 3), dos caballos $(\mathrm{DI}=1.75), 30$ pollos $(\mathrm{DI}=30)$, tres porcinos $(\mathrm{DI}=4)$, cuatro ovejas $(\mathrm{DI}=10)$ y cinco cabras $(\mathrm{DI}=\mathrm{DI})$ fueron observado. $=3$ ). Los resultados de este estudio indican que existe una gran heterogeneidad y baja pluriactividad agrícola en el proceso de producción de leche en el sur de Rio Grande do Sul, sustentada principalmente por pequeñas propiedades, basadas en el trabajo familiar y asociadas al uso de tecnologías como la inseminación artificial y ordeña mecánica.

Palabras clave: Bovinos; Perfiles sanitarios; Epidemiología.

\section{Introdução}

Segundo o censo agropecuário, realizado pelo Instituto Brasileiro de Geografia e Estatística - IBGE (2019), o Brasil possui um dos maiores rebanhos de bovinos do mundo, com mais de 213 milhões de cabeças. Dados de produção leiteira mostram que durante o mesmo ano, o país produziu 33,8 bilhões de litros, o que demonstra a sua importância no cenário agropecuário mundial (IBGE, 2019). É importante destacar que, no país, existem processos produtivos variáveis, determinados principalmente por fatores culturais e econômicos, gerando a necessidade de aumentar o conhecimento e caracterização das atividades dentro dos diferentes sistemas de produção de leite (Ribeiro et al., 2009).

O Rio Grande do Sul tem um papel de destaque na produção de leite em âmbito nacional, sendo que no ano de 2018 produziu aproximadamente 4,2 bilhões de litros, o que representou 12,5\% do total produzido no Brasil (IBGE, 2019). Na pecuária leiteira, a percepção dos produtores sobre o manejo produtivo e sanitário na bovinocultura de leite se sustenta mais na experiência prática que na aquisição de conhecimento, o que leva a uma maior dificuldade para se aumentar a quantidade e melhorar a qualidade do leite produzido (Rocha et al., 2011). Assim, a sanidade dos rebanhos destaca-se como um dos maiores desafios a serem enfrentados para que o Rio Grande do Sul continue se destacando em âmbito nacional na produção agropecuária.

A utilização de indicadores para avaliar a eficiência na pecuária leiteira tem sido uma prática constante. Alguns índices zootécnicos, como a idade ao primeiro parto, taxa de natalidade, taxa de descarte e taxa de mortalidade possuem significativa importância, pois indicam produtividade, desempenho e evolução de rebanhos, assim como, rentabilidade de sistemas de produção de leite (Lopes et al., 2009). Estudos que promovem a caracterização destes indicadores constituem uma importante ferramenta para pesquisas de novas alternativas produtivas, bem como, são importantes para orientar programas de assistência e apoio a agricultores familiares (Monteiro et al., 2007). Assim, considerando a posição de destaque do Rio Grande do Sul na bovinocultura e, devido à escassez de estudos específicos sobre o perfil da bovinocultura leiteira no estado, 
objetivou-se neste trabalho traçar o perfil zoossanitário dos rebanhos leiteiros, gerando informações que possam contribuir para aprimorar a atividade leiteira no sul do Rio Grande do Sul.

\section{Metodologia}

Foi realizado um estudo observacional seccional amostral para avaliar de forma representativa o perfil zoossanitário de 51 propriedades leiteiras localizadas geograficamente no sul do estado do Rio Grande do Sul (meridiano $52^{\circ} \mathrm{W}$ e do paralelo $31^{\circ} \mathrm{S}$ ), distribuídas em nove dos dez municípios da microrregião de Pelotas (Cristal, São Lourenço do Sul, Canguçu, Turuçu, Morro Redondo, Arroio do Padre, Cerrito, Capão do Leão e Pelotas) (Figura 1). Na região estudada, em 2017, foram ordenhadas 3,39 \% (31.273 cabeças) das vacas do estado do Rio Grande do Sul (IBGE, 2017). Em relação à produção leiteira, a região estudada produziu 20,71\% (104.758 litros) do total de leite produzido no Estado.

Figura 1. Mapa de localização da microrregião de Pelotas (área colorida) no estado do Rio Grande do sul, Brasil.

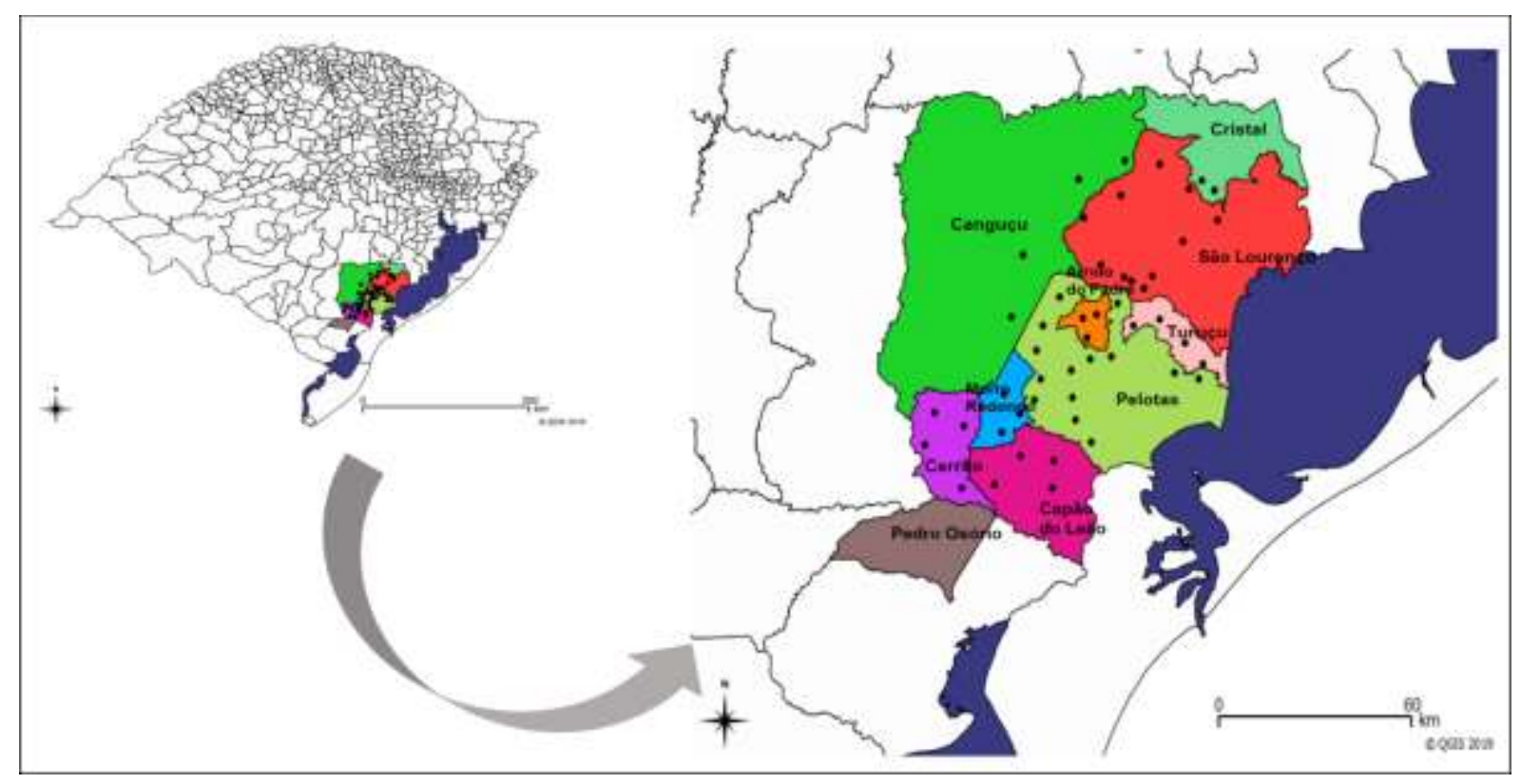

Fonte: Autores.

As propriedades foram escolhidas aleatoriamente a partir de listagens adquiridas em órgãos competentes locais, como a Cooperativa Mista de Pequenos Produtores Rurais (COOPAR) e a Empresa de Assistência Técnica e Extensão Rural (EMATER).

A abordagem inicial foi feita com o responsável local, explicando a pesquisa, seus objetivos e benefícios, e buscando sua participação. O período de realização da coleta de dados foi de abril a outubro de 2018.

Foram realizadas entrevistas a partir de formulários semiestruturados e testados previamente, com o objetivo de levantar informações sobre a caracterização dos produtores, manejo zootécnico/sanitário e produção leiteira. As entrevistas foram aplicadas por entrevistador único, médico veterinário, ao tomador de decisão presente na propriedade, sendo que no primeiro mês foi realizado o pré-teste do questionário para ajustes in loco da versão final. Portanto, o período de coleta foi de aproximadamente sete meses.

A partir das informações obtidas pelo formulário de entrevista, construiu-se um banco de dados, por meio do programa estatístico EPIDATA 3.1. Dessa forma, para cada questão formulada, fez-se a descrição dos dados pela indicação de como variam os indivíduos no grupo, ressaltando o que é típico (maior frequência) na amostra estudada, para extrair perfis e 
conclusões. Assim, foi feita a análise descritiva das principais variáveis zootécnicas e sanitárias levantadas (Rocha et al., 2011). Inicialmente, foram aplicados os testes de normalidade de Kolmogorov-Smirnov nas variáveis quantitativas avaliadas. Sendo assim, observou-se que as variáveis quantitativas avaliadas neste estudo não apresentaram distribuição normal de dados e, assim, foram utilizados a mediana e a distância interquartílica como medidas de tendência central e sua dispersão (Pestana; Gageiro, 2008). Todas as análises estatísticas foram realizadas por meio do pacote estatístico SPSS 20.0.

\section{Resultados e Discussão}

Na microrregião de Pelotas, localizada no sul do Rio Grande do Sul, foi verificado que as propriedades leiteiras apresentaram mediana de quatro moradores (DI=3), tempo na pecuária leiteira de 20 anos (DI=26) e área total foi de 40 ha (DI=57), sendo a área destinada exclusivamente a produção leiteira (instalações para os animais e áreas de descanso e pastoreio) de 23 ha $(\mathrm{DI}=32)$. As propriedades também apresentaram mediana de 20 vacas em lactação ( $\mathrm{DI}=26)$, cinco vacas secas (DI=7), efetivo de novilhas a partir de um ano de idade foi nove (DI=16) e o efetivo de terneiras com menos de um ano foi oito (DI=11), sendo o efetivo total do rebanho mediano de 44 animais (DI=63).

Também foi avaliado o efetivo de outras espécies de animais domésticos que conviviam no mesmo local de criação dos bovinos, como cães, equinos, galinhas, suínos, ovinos e caprinos. Foram observadas medianas de três cães (DI=3), dois equinos (DI=1,75), 30 galinhas ( $D I=30)$, três suínos ( $D I=4)$, quatro ovinos $(D I=10)$ e cinco caprinos ( $D I=3)$ na região estudada. Pode se observar a relativa baixa presença de outros tipos de animais de produção, sendo compatível com o fato de que a maioria das propriedades (92\%) são de produção leiteira. Este fato então indica que não ocorre um fenômeno de pluriatividade agrícola expressivo e que estas propriedades tinham o foco na produção leiteira (Winck; Thaler Neto, 2012).

Neste estudo, foram descritos os dados produtivos relacionados a distribuição da produção leiteira nas propriedades participantes. A produção destinada para a criação de terneiros foi de 10 litros/dia (DI=16) e para o consumo humano de dois litros/dia (DI=3). Em relação à produção comercializada (dia/leite), foi observado um rendimento de 250 litros (DI=550), representando então uma produção acima da média estadual considerando que a Empresa de Assistência Técnica e Extensão Rural do Rio Grande do Sul (EMATER-RS) indica que, em 2017, a média de produtividade por propriedade no estado do Rio Grande do Sul foi de 172,9 litros/dia.

A maioria das propriedades visitadas se caracterizou por apresentar tipo de mão de obra exclusivamente familiar (80,4\%), além disso, a pecuária leiteira se destaca como a principal atividade de renda (92,2\%). A maioria dos estabelecimentos não possui áreas alagadiças ou pantanosas (54,9\%). Prevalece com maior utilização entre as propriedades o sistema de ordenha mecânica ao pé (56,0\%). Em contrapartida, um estudo realizado por Patês et al. (2012) no estado da Bahia, mostrou que $93,6 \%$ das 94 propriedades de gado leiteiro estudadas realizam a prática da ordenha manual. Outro estudo feito por Júnior et al. (2015), realizado no Rio Grande do Norte aponta que todas as 28 propriedades estudadas realizavam ordenha manual com bezerro ao pé, o que indica um maior índice de tecnificação por parte dos produtores leiteiros do Rio Grande do Sul.

Aponta-se que o grau de instrução dos trabalhadores mais prevalente foi de até a $4^{\circ}$ série do ensino fundamental (54,0\%), dado que é condizente com estudos realizados por Alves Neves et al. (2011) em Petrolina e por De Oliveira et al. (2015) em São Bento, ambas cidades do estado de Pernambuco, onde foi observado respectivamente que 60,7\% e 55,55\% dos produtores entrevistados tinham o ensino fundamental incompleto. As baixas taxas de escolaridade apontadas são um reflexo do baixo investimento em políticas públicas referentes à educação no meio rural, dificultando o acesso à informaç̃es e cultura para os produtores rurais e consequentemente esse fator dificulta a adoção de novas tecnologias na produção ag rícola por parte dos produtores e o desenvolvimento dos processos produtivos que estão estritamente relacionados à uma melhor qualidade e quantidade de leite produzido (Nogueira; Aragão, 2016). 
Observou-se também que a maioria dos produtores que desejam permanecer produzindo leite para as cooperativas agroindustriais da região, está implantando em suas propriedades o sistema de ordenha mecânica canalizada e os que trabalham há mais tempo com esse sistema $(45,1 \%)$ (Tabela 1), buscam expandir a instalação dos animais, proporcionando uma melhoria na qualidade da produção leiteira.

Tabela 1: Variáveis qualitativas relacionadas às características da propriedade entre 51 propriedades leiteiras localizadas entre os 10 municípios pertencentes a microrregião de Pelotas, RS.

\begin{tabular}{lc}
\hline Variável & Geral $(\%)$ \\
\hline Tipo de mão de obra & \\
Exclusivamente familiar & 80,4 \\
Contratada fixa & 23,5 \\
Contratada temporária & 3,9 \\
Mista & 2,0 \\
& \\
Grau de instrução & \\
Ensino fundamental incompleto & 54,0 \\
Ensino fundamental completo & 6,0 \\
Ensino médio incompleto & 4,0 \\
Ensino médio completo & 20,0 \\
Ensino superior completo & 14,0 \\
& \\
Principal atividade da propriedade & \\
Produção de leite & 92,2 \\
Agricultura & 7,8 \\
& \\
Tipo de ordenha & \\
Mecânica canalizada & 45,1 \\
Mecânica ao pé & 54,9 \\
\hline
\end{tabular}

Fonte: Autores.

A partir da visualização destes dados, observa-se que, a produção de leite constitui uma atividade de grande importância econômica e está em crescente evolução na região estudada. Legislações como a Instrução Normativa n ${ }^{\circ} 62$ (IN 62) (Brasil, 2011) fazem com que produtores busquem incrementos para a melhoria da produção, pois ela determina parâmetros para Contagem de Células Somáticas (CCS) e Contagem Bacteriana Total (CBT), sendo assim há incentivo para o uso de ordenha do tipo mecânica canalizada, que é um indicador de tecnificação importante para o desenvolvimento da atividade leiteira (Angelis et al., 2016). Contudo, observou-se que, a maioria das propriedades é formada por pequenos produtores, com baixo grau de tecnificação e que vivem somente da atividade leiteira, cujo valor de recebimento pelo produto produzido está diretamente relacionado com a tecnificação da propriedade. Esse fato implica em alguns fatores que podem contribuir para a disseminação de agentes causadores de doenças ao rebanho, como a precariedade do manejo sanitário dos animais e a falta de uma infraestrutura adequada para melhor qualidade na produção (Bruhn et al., 2016).

$\mathrm{Na}$ Tabela 2 se encontram informações relacionadas às características dos rebanhos. Entre os animais que convivem no mesmo local de criação dos bovinos, observou-se uma alta frequência de aves $(84,0 \%)$, criadas de forma mista $(39,0 \%)$, soltas durante o dia e presas durante a noite ou encerradas em galinheiro (29,3\%), estando presentes na maioria dos estabelecimentos. Grande parte apresentou também criação concomitante de suínos (51,0\%) e equinos (47,1\%). As raças holandesas $(82,4 \%)$ e jersey $(72,2 \%)$ foram predominantes, o que condiz com o fato de que estas duas raças são categorizadas como de alta produção (Ledic, 2002). O sistema de criação semi-intensivo apresentou-se como maioria, sendo ele utilizado em $88,2 \%$ das propriedades observadas. 
Tabela 2: Variáveis qualitativas relacionadas às características do rebanho avaliadas entre 51 propriedades leiteiras localizadas entre os 10 municípios pertencentes à microrregião de Pelotas, RS.

\begin{tabular}{|c|c|}
\hline Variável & Geral $(\%)$ \\
\hline \multicolumn{2}{|c|}{ Equinos na propriedade } \\
\hline Não & 52,9 \\
\hline Sim & 47,1 \\
\hline \multicolumn{2}{|c|}{ Galinhas na propriedade } \\
\hline Não & 16,0 \\
\hline Sim & 84,0 \\
\hline \multicolumn{2}{|c|}{ Sistema de criação das galinhas } \\
\hline Galinheiro & 29,3 \\
\hline Soltas & 31,7 \\
\hline Misto & 39,0 \\
\hline \multicolumn{2}{|c|}{ Suínos na propriedade } \\
\hline Não & 49,0 \\
\hline Sim & 51,0 \\
\hline \multicolumn{2}{|c|}{ Ovinos na propriedade } \\
\hline Não & 86,3 \\
\hline Sim & 13,7 \\
\hline \multicolumn{2}{|c|}{ Caprinos na propriedade } \\
\hline Não & 96,1 \\
\hline Sim & 3,9 \\
\hline \multicolumn{2}{|c|}{ Raça dos bovinos da propriedade } \\
\hline Holandês & 82,4 \\
\hline Jersey & 72,5 \\
\hline Gir leiteiro & 3,9 \\
\hline Cruzas & 17,6 \\
\hline \multicolumn{2}{|c|}{ Sistema de criação das vacas } \\
\hline Intensivo & 5,9 \\
\hline Semi-intensivo & 88,2 \\
\hline Extensivo & 5,9 \\
\hline
\end{tabular}

Fonte: Autores.

$\mathrm{Na}$ Tabela 3 pode se observar que quase todas as propriedades adotam um regime alimentar misto para os bovinos (98,0\%), ou seja, produzem silagem $(96,1 \%)$ na propriedade e compram o concentrado (ração) em estabelecimentos agropecuários. O preparo da silagem para os animais é feito através do plantio de milho (100,0\%), sendo o silo do tipo trincheira $(63,3 \%)$ a preferência de grande parte dos produtores. Baixo custo, alta produção de matéria seca, alto teor energético e alta ensilabilidade são os fatores que fazem a silagem de milho ser a principal fonte energética utilizada pelos produtores leiteiros (Carvalho, 2016; Jobim et al., 2003). 
Tabela 3: Variáveis qualitativas das características do alimento destinado aos bovinos, avaliadas entre 51 propriedades leiteiras localizadas entre os 10 municípios pertencentes à microrregião de Pelotas, RS.

\begin{tabular}{lc}
\hline Variável & Geral $(\%)$ \\
\hline A propriedade produz o alimento & 2,0 \\
Sim & 98,0 \\
Misto & \\
Se sim, qual alimento & 96,1 \\
Silagem & 11,8 \\
Concentrado & 5,9 \\
Feno & \\
Tipo de silo da propriedade & 51,0 \\
Aéreo/torta & 63,3 \\
Trincheira & 2,0 \\
Bag & \\
Tipo de silagem para alimentação bovina & 100,0 \\
Milho & \\
\hline
\end{tabular}

Fonte: Autores.

As vacinas aplicadas com maior frequência, além das obrigatórias (aftosa e brucelose) previstas pelo Manual de Legislação dos Programas Nacionais de Saúde Animal do Brasil (Brasil, 2009), são as vacinas para raiva bovina (51,0\%), rinotraqueíte infecciosa bovina (47,1\%), Diarréia Viral Bovina (43,1\%), leptospirose $(39,2 \%)$ e clostridiose $(11,8 \%)$. Em um estudo feito por Santos et al., 2018 na mesma região do Rio Grande do Sul baseado em 162 casos de bovinos de até 12 meses de idade com sinais neurológicos, foi apontado que $48(29,64 \%)$ desses casos eram de raiva bovina, dado que corrobora com as práticas de vacinação atuais para tal doença, tendo em vista que a raiva bovina é uma enfermidade comum nessa região do estado. Foi observado que o manejo reprodutivo mais utilizado nos rebanhos leiteiros é o de inseminação artificial (90,2\%), seguida da monta natural $(19,6 \%)$ e transferência de embrião $(2,0 \%)$. Tendo em vista que a transferência de embrião é uma técnica de manejo reprodutivo pouco utilizado por estes produtores, pode se apontar que nessas propriedades há um baixo investimento em tecnificação produtiva, nesse sentido, ações podem ser tomadas em busca de aumento da produtividade e melhor manejo reprodutivo, como a capacitação e especialização dos colaboradores, adoção de procedimentos operacionais padrão (POPs) e a adesão de incentivos de desempenho por parte das cooperativas em que os produtores estão inseridos (De Sousa Neres et al., 2017). 
Tabela 4: Variáveis qualitativas relacionadas às características de manejo vacinal e reprodutivo avaliadas entre 51 propriedades leiteiras com menor ou maior frequência de vacas soropositivas (+) para N. caninum (ELISA indireto), microrregião de Pelotas, RS.

\begin{tabular}{lc}
\hline Variável & Geral (\%) \\
\hline Quais vacinas são aplicadas nos bovinos & 39,2 \\
Leptospirose & 51,0 \\
Raiva & 47,1 \\
Rinotraqueíte Infecciosa Bovina & 43,1 \\
Diarréia Viral Bovina & 11,8 \\
Clostridiose & \\
Manejo reprodutivo & 51,0 \\
Monta natural & 63,3 \\
Inseminação artificial (IA) & 2,0 \\
Transferência de embriões & \\
\hline
\end{tabular}

Fonte: Autores.

Quando há necessidade de reposição de animais nos plantéis, os produtores o fazem com animais comprados de propriedades vizinhas $(93,5 \%)$ (Tabela 6). Observou-se que a maioria dos estabelecimentos adota rodízio de piquetes $(94,1 \%)$ como forma de proporcionar uma melhor disponibilidade de alimento para os animais. Apenas 4,0\% dos produtores utilizam piquete de quarentena para os animais recém-introduzidos na propriedade antes de incorporá-los ao rebanho, o que caracteriza uma problemática para estas propriedades, tendo em vista que a compra de animais com a utilização de piquetes de quarentena é considerada uma boa prática de manejo produtivo, sendo ela importante para identificar possíveis animais infectados por diversas doenças infecciosas como a brucelose, tuberculose, diarreia viral bovina e a rinotraqueíte bovina, sendo assim, a não aplicação desta técnica se caracteriza como um fator de risco para que estas enfermidades se disseminem pelos rebanhos (Piva Filho; Queiroz, 2013; Barbosa et al., 2019). Grande parte das propriedades não expõem seus animais em eventos agropecuários $(90,2 \%)$ e utiliza como critério de descarte a idade avançada $(76,5 \%)$.

Foi possível observar que, nos dois últimos anos, foram diagnosticadas doenças $(82,4 \%)$ na maioria dos rebanhos, principalmente casos de tristeza parasitária bovina e mastite clínica e que mais da metade do total de propriedades não possuem assistência veterinária (60,8\%). Na maioria dos casos as carcaças dos animais mortos ou de fetos abortados são recolhidas do campo $(72,2 \%)$ e logo após enterradas $(56,9 \%)$ em local afastado das instalações dos rebanhos bovinos, ambas ações consideradas como boas práticas de manejo sanitário, pois o descarte inadequado de carcaças de animais ou fetos mortos são considerados como fatores de risco para o surgimento e disseminação de doenças como a neosporose (Fávero et al., 2017; Gindri et al., 2018).

Recentemente em estudo realizado por Cvetojevic et al. (2018), na Sérvia, foi verificado que entre os rebanhos estudados (cinco), somente em uma propriedade a placenta ou fetos abortados foram retirados do piquete de maternidade, nas demais propriedades o material resultante de nascimentos normais ou abortos foram deixados na maternidade para posterior descarte juntamente com as fezes dos animas. Apesar de ser observado, no presente estudo, que a maioria das propriedades estudadas recolhe a carcaça de animais mortos ou de fetos abortados, foi verificado que a placenta desses bovinos não é recolhida do campo na maioria das propriedades $(90,0 \%)$.

A observação da presença de ratos na área de alimentação dos bovinos $(78,4 \%)$ foi relatada em boa parte dos estabelecimentos, conforme mostra a Tabela 5, medidas de controle para diminuir a população de roedores (92,0\%) são utilizadas em quase todas as propriedades. A presença de roedores é um fator de risco conhecido para a ocorrência da leptospirose, uma alta incidência de roedores nos estabelecimentos rurais, particularmente em áreas em que os bovinos têm 
contato direto pode levar a um aumento no número de casos da doença, principalmente quando há uma taxa de vacinação baixa dos rebanhos (Paixão et al., 2016; Baroni et al., 2019).

Tabela 5: Variáveis qualitativas relacionadas ao manejo sanitário, avaliadas entre 51 propriedades leiteiras localizadas entre os 10 municípios da microrregião de Pelotas, RS.

\begin{tabular}{lc}
\hline Variável & Geral (\%) \\
\hline Reposição dos animais & 6,5 \\
Criados na propriedade & 93,5 \\
Comprados de propriedades vizinhas/próximas & 9
\end{tabular}

A propriedade adota rodízio de piquetes

$\begin{array}{lr}\text { Não } & 5,9 \\ \text { Sim } & 94,1\end{array}$

Animais recém adquiridos ficam em piquete de quarentena

Nunca compra $\quad 16,0$

Não $\quad 80,0$

Sim $\quad 4,0$

Participação de animais em eventos

Não $\quad 90,2$

Sim $\quad 9,8$

Qual é o critério de descarte das vacas
Idade avançada

Problemas reprodutivos/infertilidade $\quad 51,0$

$\begin{array}{ll}\text { Queda na produção de leite } & 15,7\end{array}$

Foram diagnosticadas doenças no rebanho nos dois últimos anos
$\quad$ Não

Sim $\quad 82,4$

A propriedade tem assistência veterinária
Não

Sim $\quad 39,2$

Carcaças de animais adultos mortos ou de fetos são recolhidas do campo

$\begin{array}{ll}\text { Não } & 27,1\end{array}$

$\begin{array}{lr}\text { Sim } & 72,9\end{array}$

Destino das carcaças dos animais mortos

Deixada no campo $\quad 23,5$

Queimada $\quad 7,8$

$\begin{array}{lr}\text { Enterrada } & 56,9\end{array}$

Medidas para o controle de roedores
Não

Sim $\quad 92,0$

Presença de ratos na área de alimentação dos bovinos

Não $\quad 21,6$

$\begin{array}{ll}\mathrm{Sim} & 78,4\end{array}$ 
Nesse estudo, foram avaliadas algumas variáveis referentes ao manejo da vaca gestante. Foi verificado que pouco mais da metade das propriedades possui um piquete de maternidade $(54,0 \%)$ para o pré-parto das vacas e que não realizam na sua grande maioria algum tipo de vacinação nesse período $(97,9 \%)$. A maioria dos rebanhos apresenta uma condição corpórea média na época do parto $(90,2 \%)$ e observa-se que $48,0 \%$ das vacas avaliadas apresentaram dificuldades no parto.

Ao comparar os resultados verificados neste trabalho com outros que avaliaram o perfil do produtor de leite da região sul do Rio Grande do Sul, é possível observar a existência, na mesma região, de sistemas produtivos diferenciados entre si, principalmente em relação a fatores relacionados ao uso de tecnologias, tais como uso de ordenha mecânica e inseminação artificial, com impacto nos índices de produção e produtividades dos rebanhos.

\section{Conclusão}

Os resultados deste estudo indicam que, no sul do Rio Grande do Sul, existe uma expressiva heterogeneidade durante o processo de produção, porém a maior parte do leite é produzida em pequenas propriedades que utilizam a mão de obra familiar, associada ao uso de tecnologias modernas, tais como a inseminação artificial e ordenha mecânica.

Trabalhos como este ajudam a caracterizar as condições dos processos produtivos das propriedades envolvidas na pecuária leiteira a partir da avaliação do perfil zoossanitário. É pertinente que estudos do gênero sejam realizados tanto no contexto da produção leiteira quanto em qualquer outro segmento pecuário brasileiro, pois os mesmos podem auxiliar profissionais destes meios na melhor compreensão das condições materiais dos sistemas produtivos em que atuam.

\section{Referências}

Angelis, D., Sousa, M. R. P. de, \& Oliveira, V. (2016). Qualidade Do Leite, Obtido Por Ordenha Manual E Mecanizada, Recebido Em Um Laticínio Do Município De Argirita-MG. Veterinária Notícias Veterinary News. 22(1), 27-31.

Barbosa, V. M., Gondim, C. C., Nasciutti, N. R., Oliveira, P. M., Alfieri, A. A., Fritzen, J. T. T., Headley, S. A., Saut, A. M., Berssaneti, F. T., \& Saut, J. P. J. (2019). Fatores de risco associados à infecção viral (BoHV-1 e BVDV) em rebanhos leiteiros mestiços com problemas reprodutivos, no município de Uberlândia, MG. Arquivo Brasileiro de Medicina Veterinária e Zootecnia. 71(4), 1243-1250.

Baroni, A. E., Bossanelli, G., Boelcke R. B., \& Almeida, L. C. (2019). Prevalência soroepidemiológica de Leptospira spp. em rebanhos bovinos leiteiros da mesorregião do Rio Doce no Estado do Espírito Santo. PUBVET. 14(2), 1-11.

Brasil, Ministério da Agricultura, pecuária e Abastecimento (2011). Instrução Normativa nº 62, de 29 de dezembro de 2011 . Resolve aprovar o Regulamento Técnico de Produção, Identidade e Qualidade do Leite tipo A, o Regulamento Técnico de Identidade e Qualidade de Leite Cru Refrigerado, o Regulamento Técnico de Identidade e Qualidade de Leite Pasteurizado e o Regulamento Técnico da Coleta de Leite Cru Refrigerado e seu Transporte a Granel. Diário Oficial da União.

Brasil, Ministério da Agricultura, pecuária e Abastecimento (2009). Manual de Legislação: programas nacionais de saúde animal do Brasil.

Bruhn, F. R. P., Daher, D. O., Rrocha, C. M. B. M., Barbieri, J. M., Lucci, J. R., \& Guimarães, A. M, (2016). Zootechnical profile of the dairy farms in southern Minas Gerais State, Brazil. Archivos Latinoamericanos de Producción Animal. 24(3), 123-129.

Carvalho, R. M. de (2016). Avaliação da silagem de milho em fazendas leiteiras de Patos de Minas, MG. [Dissertação de Mestrado]. Faculdade de Ciências Veterinárias da Universidade Federal de Uberlândia.

Cvetojevic Đ., Milicevic V., Kureljusic B., \& Savic B. Đ. (2018). Seroprevalence of Neospora caninum in dairy cows in Belgrade city area, Serbia. Journal of the Hellenic Veterinary Medical Society. 69(2), 979-983.

Almeida, T. J. O., Araújo, V. V., Feitosa, P. J. S., \& Da Silva, A. F. A. (2015). Perfil sociocultural de produtores de leite bovino do município de São Bento do Una (PE) e suas implicações sobre o manejo da ordenha. Revista Brasileira de Higiene e Sanidade Animal. 9(1), $122-135$.

De Sousa Neres, L., Junior, J. B. L., Santos, M. A. S., Noronha, G. N., Bezerra, A. S., \& Silva, A. G. M. (2017). Caracterização da pecuária leiteira no município de Tailândia, Estado do Pará, Brasil. Revista de Ciências Agrárias Amazonian Journal of Agricultural and Environmental Sciences. 60(3), 278-285.

EMATER. Rio Grande do Sul/ASCAR (2017). Relatório socioeconômico da cadeia produtiva do leite no Rio Grande do Sul: 2017.

Fávero, J. F., Da Silva, A. S., Campigotto, G., Machado, G., De Barros, L. D., Garcia, J. L., Vogel, F. F., Mendes, R. E., \& Stefani, L. M. (2017). Risk factors for Neospora caninum infection in dairy cattle and their possible cause-effect relation for disease. Microbial pathogenesis. 110, $202-207$.

Gindri, P. C., Mion, B., Pradieé, J., Bialves, T. S., De Souza, G. N., Dellagostin, O. A., Scheider, A., \& Pegoraro, L. M. C. (2018). Seroprevalence estimate and associated risk factors for neosporosis in dairy cattle in the northwest region of Rio Grande do Sul State, Brazil. Ciência Rural. 48(7). 
Instituto Brasileiro de Geografia e Estatística [IBGE] (2017). Censo agro 2017. Brasil. https://censoagro2017.ibge.gov.br/templates/censo_agro/res ultadosagro/pecuaria.html?localidade $=43 \&$ tema $=75653$

Instituto Brasileiro de Geografia e Estatística [IBGE] (2019). Produção da Pecuária Municipal 2018. Rio de Janeiro, Brasil. https://cidades.ibge.gov.br/br asil/rs/pes quisa/18/16459?indicador=16559\&localidade $1=0 \&$ ano $=2018$

Jobim, C. C., Branco, A. B., \& Santos, G. T. (2003). Silagem de grãos úmidos na Alimentação de bovinos leiteiros. V Simpósio Goiano sobre Manejo e Nutrição de Bovinos de Corte e Leite. Goiânia, Goiás, 357-376.

Galvão Júnior, J. G. B., Rangel, A. H. N., Guilhermino, M. M., Novaes, L. P., \& Medeiros, H. R. (2015). Perfil dos sistemas de produção de leite bovino no seridó potiguar. HOLOS. 2, 130-141.

Ledic, I. L., Tonhati, H., Verneque, R. S., Faro, L. E., Martinez, M. L., Costa, C. N., Pereira, J. C. C., Fernandes, L. O., \& Albuquerque, L. G. (2002). Estimativa de parâmetros genéticos, fenotípicos e ambientes para as produções de leite no dia do controle e em 305 dias de lactação de vacas da raça Gir. Revista Brasileira de Zootecnia. 31(5), 1953-1963.

Lopes, M. A., Demeu, F. A., Santos, G., \& Cardoso, M. G (2009). Impacto econômico do intervalo de partos em rebanhos bovinos leiteiros. Ciencia e Agrotecnologia. 33(1), 1908-1914.

Monteiro, A. A., Tamanini, R., Silva, L. C. C., Mattos, M. R., Magnani, D. F., D’Ovidio, L., Nero, L. A., Barros, M. A. F., Pires, E. M. F., Paquereau, B. P. D., \& Beloti, V (2007). Características da produção leiteira da região do agreste do estado de Pernambuco, Brasil. Semina: Ciências Agrárias. 28(4), 665-674.

Nogueira, D., \& Aragão, M. C. O. (2016). A pecuária leiteira bovina no município de Olivença-AL: o contexto socioeconômico dos produtores. Diversitas Journal. 1(1), 94-99.

Neves, A. L. A., Pereira, L. G. R., Santos, R. D. dos, Araujo, G. G. L. de, Carneiro, A. V., Moraes, S. A. de, Spaniol, C. M. O., \& Aragão, A. S. K. de (2011). Caracterização dos produtores e dos sistemas de produção de leite no perímetro irrigado de Petrolina/PE. Revista Brasileira de Saúde e Produção Animal. 12(1), 209-223.

Paixão, A. P., Santos, H. P., Alves, L. M. C., Pereira, H. M., Carvalho, R. F. B., Filho, V. M. C., Oliveira, E. A. A., Soares, D. M., \& Beserra, P. A. (2016). Leptospira spp. em bovinos leiteiros do estado do Maranhão, Brasil: frequência, fatores de risco e mapeamento de rebanhos reagentes. Arquivos do Instituto Biológico. 83

Patês, N. M. S., Figueiredo, M. P., Pires, A. J. V., De Carvalho, G. G. P., Da Silva, F. F., Fries, D. D., Bonomo, P., \& Rosa, R. C. C. (2012). Aspectos produtivos e sanitários do rebanho leiteiro nas propriedades do sudoeste da Bahia. Revista Brasileira de Saúde e Produção Animal. 13(3), 825-837.

Piva Filho, G. L., \& Queiroz, L. H (2013). Prevalência da brucelose e tuberculose bovina e percepção de riscos de pequenos produtores de leite do município de paranaiba-mato grosso do sul. Ars Veterinaria. 29(4), 78-78.

Pestana, M. H., \& Gageiro, J. N. (2008). Análise de dados para ciências sociais - A complementariedade do SPSS. Ed. Silabo, (5a ed.), 692-692.

Ribeiro, A. B., Tinoco, A. F. F., Lima, G. F. C., Guilhermino, M. M., \& Rangel, A. H. N. (2009). Produção e composição do leite de vacas Gir e Guzerá nas diferentes ordens de parto. Revista Caatinga. 22(3), 46-51.

Rocha, C. M. B. M., Leite, R. C., Bruhn, F. R. P., Guimaraes, A. M., \& Furlong, J. (2011). Perceptions about the biology of Rhipicephalus (Boophilus) microplus among milk producers in Divinópolis, Minas Gerais. Rev Bras Parasitol Vet. 20(4), 289-294.

Santos, B. L., Estima-Silva, P., Coelho, A. C. B., Oliveira, P. A., Soares, M. P., Sallis, E. S. V., Bruhn, F. R. P., \& Schild, A. L. (2018). Doenças do sistema nervoso central de bezerros no sul do Rio Grande do Sul: uma contribuição ao diagnóstico diferencial. Pesquisa Veterinária Brasileira. 38(4), 685-691.

Winck, C. A., \& Neto, A. T. (2012). Perfil de propriedades leiteiras de Santa Catarina em relação à Instrução Normativa 51. Revista Brasileira de Saúde e Produção Animal. 13(2), 296-305. 